\title{
Resisting Urges to Self-Injure
}

\author{
E. David Klonsky and Catherine R. Glenn
}

Stony Brook University, New York, USA

\begin{abstract}
The present study explored whether and how self-injurers attempt to resist urges to harm themselves. Participants were 39 young adults with a history of skin cutting and other nonsuicidal self-injurious behaviors. A structured interview assessed the prevalence and perceived helpfulness of 48 methods for resisting self-injurious urges. Ninety percent of participants indicated that they had made efforts to resist urges to self-injure. These individuals had used an average of 16 different methods, and reported that they were successful in resisting the urges most of the time. "Keeping busy" and "Being around friends" were the most common methods used to resist self-injurious urges. However, "Doing sports or exercise" and "Removing the means/instruments typically used to self-harm from the home" were rated as being the most helpful for resisting self-injurious urges. Findings have implications for enhancing treatment and guiding future research.
\end{abstract}

Keywords: Non-suicidal self-injury, self-mutilation, psychotherapy, behavior therapy.

\section{Introduction}

Self-injury is defined as the deliberate and direct injuring of body tissue without suicidal intent for purposes not culturally sanctioned. This behavior has also been referred to by other names, including deliberate self-harm, self-mutilation, non-suicidal self-injury, and selfinjurious behavior. Self-injury is a growing public health concern due to its disproportionate frequency in adolescents and young adults (Ross and Heath, 2002; Whitlock, Eckenrode and Silverman, 2006) and its strong association with psychopathology (Hawton, Rodham, Evans and Weatherall, 2002; Klonsky, Oltmanns and Turkheimer, 2003).

Self-injury most often occurs in psychiatric populations. Rates of self-injury are estimated to be $21 \%$ among adult psychiatric populations (Briere and Gil, 1998), and 40-61\% among adolescent inpatient populations (Darche, 1990; DiClemente, Ponton and Hartley, 1991). Selfinjury has also been reported to occur in $4 \%$ of adult community samples (Briere and Gil, 1998; Klonsky et al., 2003). Rates are particularly high in young populations, as $8 \%$ of children ages 12 to 14 (Hilt, Nock, Lloyd-Richardson and Prinstein, in press), 14-15\% of adolescents (LayeGindhu and Schonert-Reichl, 2005; Ross and Heath, 2002), and 14-17\% of college students (Favazza, DeRosear and Conterio, 1989; Whitlock et al., 2006) report having self-injured.

Self-injury typically begins between 13 and 16 years of age (Muehlenkamp and Gutierrez, 2004; Rodham, Hawton and Evans, 2004). There is some indication that self-injury is more

Reprint requests to E. David Klonsky, Department of Psychology, Stony Brook University, Stony Brook, New York 11794-2500, USA. E-mail: eklonsky@notes.cc.sunysb.edu 
common now than in the past. For example, in several studies lifetime rates are higher in younger than older participants (Briere and Gil, 1998; Zlotnick, Mattia and Zimmerman, 1999). Regarding types of self-injury, many studies suggest that cutting is the most common form while less common forms include self-hitting, pinching, scratching, biting, and burning (Briere and Gil, 1998; Laye-Gindhu and Schonert-Reichl, 2005; Ross and Heath, 2002). However, Whitlock et al. (2006) found that severe skin-scratching was the most common form in college students. Most self-injurers report having used multiple methods (Gratz, 2001; Herpetz, 1995; Whitlock et al., 2006). Studies on the functions of self-injury indicate that self-injury serves varied purposes, including reducing negative feelings, punishing oneself, and eliciting attention from others (Briere and Gil, 1998; Brown, Comtois and Linehan, 2002; Favazza et al., 1989; Nock and Prinstein, 2004; Rodham et al., 2004). An empirical review suggests that the most common function of self-injury is the regulation of negative affect (Klonsky, 2007), sometimes referred to as relieving tension or stopping bad feelings.

Self-injury is associated with many types of psychopathology. Self-injurers score higher than non self-injurers on measures of depression and anxiety (Andover, Pepper, Ryabchenko, Orrico and Gibb, 2005; Hawton et al., 2002; Klonsky et al., 2003). In addition, self-injury is correlated with many personality disorders, including the borderline, dependent, schizotypal, and avoidant personality disorders (Klonsky et al., 2003). Although self-injurers exhibit considerable diagnostic heterogeneity (Klonsky \& Olino, in press), self-injury exhibits a particularly large association with borderline personality disorder (Andover et al., 2005; Klonsky et al., 2003; Stanley, Gameroff, Michalsen and Mann, 2001). Even though selfinjury can be distinguished from suicide attempts on the basis of the behavior's intent and lethality, self-injurers are more likely to attempt suicide in comparison to non self-injurers (Brown et al., 2002; Muehlenkamp and Gutierrez, 2004).

The demographic correlates of self-injury are not clear. Some studies indicate higher rates in females (Muehlenkamp and Gutierrez, 2004; Whitlock et al., 2006), while others find no gender differences (Briere and Gil, 1998; Klonsky et al., 2003). There may be gender differences in the forms of self-injury used by males and females rather than differences in overall prevalence rates, as males report more self-hitting and females more cutting (Laye-Gindhu and SchonertReichl, 2005). A recent study of psychiatric patients examined differences between male and female self-injurers (Claes, Vandereycken and Vertommen, 2007). In this study, males were found to engage in more burning, to experience more pain, and to use self-injury to get attention from others (socially-oriented functions). In comparison, females engaged in more cutting, reported more interpersonal complaints, and more sexual abuse. In addition, there appears to be some racial disparity. Higher rates of self-injury are found in Caucasian than non-Caucasian populations (Gratz, 2006; Ross and Heath, 2002; Whitlock et al., 2006).

Some suggest that child abuse (sexual, physical, and emotional) may contribute to the development of self-injury, but research in this area is mixed. Hawton et al. (2002) reported that $10 \%$ of sexually abused males and almost $30 \%$ of sexually abused females had self-injured. However, a recent meta-analysis found that childhood sexual abuse (CSA) accounts for less than $6 \%$ of the variance in the development of self-injurious behaviors and is therefore not likely to play an important etiological role (Klonsky and Moyer, in press). Childhood physical abuse may be more strongly related to self-injury than CSA (Carroll, Schaffer, Spensley and Abramowitz, 1980; Evren and Evren, 2005; Zoroglu et al., 2003; Zweig-Frank, Paris and Guzder, 1994) ; however, further research is needed. 
Treatment of self-injury can be challenging. One therapy showing promise with self-injuring populations is Dialectical Behavioral Therapy (DBT), which focuses on cognitive-behavioral strategies to increase skills in mindfulness, effective communication, and emotion regulation (Linehan, 1993; Brown, 1998). Research has documented DBT's success in reducing selfinjury, but most of the samples were women diagnosed with Borderline Personality Disorder (Linehan, Armstrong, Suarez, Allmon and Heard, 1991; Linehan, Heard and Armstrong, 1993; Linehan et al., 2006). Additionally, Acceptance-Based Emotion Regulation Group Intervention is a newer therapy that focuses on decreasing self-injury by teaching more adaptive ways of responding to emotions. Preliminary research shows positive effects on emotional dysregulation and self-injury (Gratz and Gunderson, 2006). However, these studies have only examined treatments for self-injury in borderline populations. Little research has addressed treatment of self-injury in community samples of adolescents and young adults, where between $8-15 \%$ self-injure (Hilt et al., in press; Laye-Gindhu and Schonert-Reichl, 2005; Ross and Heath, 2002). In addition, not much is known about the effects of treatment over the long term, and many people receiving treatment continue to self-injure, even if less frequently (Scheel, 2000; Koerner and Dimeff, 2000; Swenson, Torrey and Koerner, 2002) . Therefore, efforts to enhance treatment for self-injury are ongoing.

One challenge for therapists is that many self-injurers spend less than a few minutes contemplating their behavior before engaging in a self-injurious episode (Nock and Prinstein, 2005). Therefore, there may be little time to intervene between the urge to self-injure and the actual self-injury. Identifying ways of resisting urges to self-injure, including those that are most effective, could enhance the treatment of self-injury. Such knowledge would aid therapists working with these clients, as well as researchers interested in constructing effective treatments for these patients. Toward this aim, the present study examined the prevalence and perceived helpfulness of methods for resisting self-injurious urges in 39 young adults with a history of repeated self-injury.

\section{Method}

\section{Participants}

Participants were 39 young adults ( 30 women, 9 men) from a college sample who screened positive for non-suicidal, deliberate skin-cutting and completed an interview about their selfinjury. Participants could choose between receiving course credit or $\$ 15$ for their participation in the study. The mean age of the sample was 19.4 years $(S D=2.2)$. The racial composition of the sample was 89\% Caucasian, 4\% African American, 4\% Asian, and 2\% Hispanic.

\section{Procedure}

Undergraduates in low-level psychology courses were screened over the courses of two academic years $(N=2,776)$. For the purposes of the present study, a measure was included to assess history of non-suicidal, but deliberate self-injury. This was assessed using the following item: "About how many times in your life have you intentionally (i.e., on purpose) cut your wrists, arms, or other areas of your body (e.g., with a knife, scissors, razor blade, etc.) even though you weren't trying to commit suicide?" Fifty-three individuals who indicated a history of five or more instances of skin-cutting and who had not yet fulfilled their research requirement 
(or alternative assignment) were invited by e-mail to participate in a study on self-injury. The threshold of five or more cutting episodes was chosen to ensure a clinically relevant sample that could reasonably respond to questions about resisting urges to self-injure. Forty-eight agreed to participate. At the interview, the original screening questions were presented a second time to ensure participants met study criteria. Nine of the 48 participants were excluded at that point because they did not meet the central criteria for participation in the study (at least five skincutting episodes): five had fewer than five cutting episodes, two reported misunderstanding the screening measure, and the other two could not recall how they reported or responded to the screening measure. The protocol was administered to the remaining 39 students.

\section{Measure}

A structured interview was designed to assess efforts by self-injurers to resist harming themselves. Participants were presented with 48 methods that could be used to resist urges to self-injure that were drawn from websites by and for self-injurers (see Table 1 for a complete list of methods assessed). Participants were asked to make two judgments about each of the methods presented to them. First, they were asked to rate how often they had used a particular method on a 5-item scale, 1-Never, 2-Rarely, 3-Sometimes, 4-Usually, 5-Always. Second, for each method that participants had tried, they were asked to rate how helpful they found that method to be for resisting urges to self-injure on a 3-item scale, 1-very helpful, 2-somewhat helpful, 3-not at all helpful. Lastly, a subset of participants $(n=30)$ were asked what percentage of the time they were successful in resisting urges to self-injure. Specifically they were asked: "In those instances in which you had an urge to self-harm and tried a "very helpful' method, approximately what percent of the time were you successful in avoiding self-harm?" and "Similarly, in those instances in which you had an urge to self-harm and tried a 'somewhat helpful' method, approximately what percent of the time were you successful in avoiding self-harm?"

\section{Results}

\section{Treatment history}

Sixty-four percent of the participants reported having received some form of mental health treatment: $59 \%$ had participated in outpatient counseling, 39\% had taken psychiatric medication, and $13 \%$ had received treatment in an inpatient psychiatric hospital.

\section{History of self-injury}

According to self-reported lifetime estimates, participants cut themselves a mean of 17 times $(S D=13$; Range $=5-50)$. Ninety-two percent of participants reported that they had engaged in additional self-injurious behaviors as well, including banging body parts against something (endorsed by $51 \%$ of the sample), severe scratching (46\%), burning (39\%), sticking sharp objects into skin $(28 \%)$, interfering with wound healing (26\%), severe skin picking or pinching (23\%), biting (21\%), hitting (13\%), and rubbing skin against rough surfaces (3\%). The mean number of methods of self-injury endorsed was $4(S D=2)$. The mean age of onset of cutting 
Table 1. Frequency with which methods for resisting urges to self-injure were used by participants

\begin{tabular}{|c|c|}
\hline Coping method & $\%$ endorsed $^{a}$ \\
\hline Keeping busy & 82.4 \\
\hline Being around friends & 80.0 \\
\hline Talking to someone about how you feel & 74.3 \\
\hline Writing about how you feel & 74.3 \\
\hline Talking to friends & 71.4 \\
\hline Interacting with someone who is nice to you & 68.6 \\
\hline Thinking of someone who cares about you & 65.7 \\
\hline Finding someone who is understanding & 65.7 \\
\hline Doing sports or exercise recreationally & 65.7 \\
\hline Listening to music & 62.9 \\
\hline Anticipating others' reactions to self-harm & 60.0 \\
\hline Being around people & 57.1 \\
\hline Doing mindless activities & 48.6 \\
\hline Reading & 42.9 \\
\hline Writing poetry & 42.9 \\
\hline Finding a less chaotic environment & 40.0 \\
\hline Taking a hot bath or shower & 40.0 \\
\hline Thinking about how much it will hurt & 39.4 \\
\hline Thinking about others with similar problems & 37.1 \\
\hline Receiving outpatient counseling & 37.1 \\
\hline Removing the means/instrument typically used to self-harm from home & 35.5 \\
\hline Talking to your doctor/professional & 34.3 \\
\hline Religion/spirituality & 34.3 \\
\hline Closing eyes and thinking calming thoughts & 34.3 \\
\hline Setting limits on frequency of self-harm & 34.3 \\
\hline Doing household chores & 34.3 \\
\hline Relaxing & 28.6 \\
\hline Antidepressants & 28.6 \\
\hline Chatting on internet & 20.0 \\
\hline Organized sports & 18.2 \\
\hline Working with paint, clay, play-doh & 17.1 \\
\hline Harming objects (towels, magazine, etc) & 17.1 \\
\hline Playing a musical instrument & 14.3 \\
\hline Anxiety meds & 14.3 \\
\hline Learning something new & 8.6 \\
\hline Drawing on arms with red pen/marker & 8.6 \\
\hline Snapping wrist with rubber band & 8.6 \\
\hline Mood stabilizers & 5.9 \\
\hline Massaging area you want to harm & 5.7 \\
\hline Cooking & 5.7 \\
\hline Spending time in psychiatric hospital & 5.7 \\
\hline Tranquilizers & 5.7 \\
\hline Holding ice in your hand & 2.9 \\
\hline Mutilating fruit or vegetable or other food & 2.9 \\
\hline Group therapy & 2.9 \\
\hline Pastoral/religious counseling & 2.9 \\
\hline Chiropractor & 0.0 \\
\hline Acupuncture & 0.0 \\
\hline
\end{tabular}

${ }^{a}$ These figures indicate the percentage of participants who endorsed having used each method at least once for the purpose of resisting an urge to self-injure. 
was $14(S D=2)$ with a mean duration of 3 years $(S D=2)$. Seventy-two percent of participants reported that they had self-injured in the past year.

\section{Most common and most helpful methods}

Thirty-five of the 39 participants $(89.7 \%)$ reported that they had tried to resist urges to selfinjure. These 35 participants were presented with a list of 48 methods for resisting urges (see Table 1). For each method, participants indicated if they had used the method and, if so, whether the method was very helpful, somewhat helpful, or not helpful at all for resisting urges to self-injure. Forty-six of the 48 methods assessed had been utilized by more than one person, and the average person endorsed 16 methods $(S D=6)$. As indicated in Table 1, the most common methods were: "Keeping busy" (endorsed by $82.4 \%$ of participants), "Being around friends" (80.0\%), "Talking to someone about how you feel" (74.3\%), and "Writing about how you feel" (74.3\%).

Table 2 presents the most helpful methods for resisting urges to self-injure. "Doing sports or exercise recreationally" was rated as "very helpful" by $65.2 \%$ of those who used this method. Other very helpful methods include: "Removing the means/instrument typically used to self-harm from home" (63.6\%), "Finding someone who is understanding" (60.9\%), and "Turning to religion/spirituality" (50.0\%). Participants were also asked to indicate how often they were able to resist self-injurious urges. On average, participants reported successfully resisting urges to self-injure $85 \%$ of the time $(S D=14)$ when using a "very helpful" method, and $52 \%$ of the time $(S D=20)$ when using a "somewhat helpful" method.

\section{Discussion}

The present study examined self-injurers' attempts to resist urges to harm themselves. Results indicate that most self-injurers strive to resist self-injurious urges. Results also suggest that individuals employ a range of methods to resist urges. In the present study, 46 methods were endorsed by multiple persons and the average person endorsed more than a dozen methods. The most common methods for resisting urges were: "Keeping busy", "Being around friends", and "Talking to someone about how you feel". In general, participants reported being able to resist most of their self-injurious urges. For example, participants felt they could successfully resist urges about half the time when trying methods perceived as "Somewhat helpful", and most of the time when trying methods perceived as "Very helpful". Interestingly, methods identified as being the most helpful were not the ones employed most often. The most helpful methods were judged to be: "Doing sports or exercise recreationally," "Removing the means/instrument typically used to self-harm from home" and "Finding someone who is understanding".

It is interesting to note that the most helpful methods for resisting urges to self-injure are not also the most widely used. This discrepancy may occur for a couple of reasons. From a practical standpoint, the most widely used methods are perhaps the most convenient or accessible. Methods such as "Keeping busy" or "Being around friends" may be easier than "Doing sports or exercise recreationally" or "Removing the means/instrument typically used to self-injure from home". In addition, the most helpful methods may not be used as often because they are not the most intuitive. "Talking to others about how you feel" may instinctively seem more effective in coping with feelings that prompt self-injury than engaging in physical 
Table 2. Helpfulness ratings of methods for resisting urges to self-injure

\begin{tabular}{lcccr}
\hline & & & \multicolumn{2}{c}{ How helpful $^{\mathrm{b}}$} \\
\cline { 3 - 5 } Coping method & & & & \\
\cline { 3 - 5 } \# endorsed & Very & Somewhat & Not at all \\
\hline Doing sports or exercise recreationally & 26 & 65.2 & 30.4 & 4.3 \\
Removing the means/instrument typically & 13 & 63.6 & 18.2 & 18.2 \\
$\quad$ used to self-harm from home & & & & \\
Finding someone who is understanding & 26 & 60.9 & 30.4 & 8.7 \\
Turning to religion/spirituality & 13 & 50.0 & 50.0 & 0.0 \\
Being around friends & 31 & 42.9 & 50.0 & 7.1 \\
Writing about how you feel & 29 & 42.3 & 42.3 & 15.4 \\
Thinking of someone who cares about you & 26 & 39.1 & 56.5 & 4.3 \\
Talking to someone about how you feel & 29 & 38.5 & 50.0 & 11.5 \\
Anticipating others' reactions to self-harm & 23 & 38.1 & 47.6 & 14.3 \\
Keeping busy & 32 & 35.7 & 57.1 & 7.1 \\
Talking to friends & 28 & 32.0 & 60.0 & 8.0 \\
Antidepressants & 11 & 30.0 & 30.0 & 40.0 \\
Writing poetry & 17 & 26.7 & 73.3 & 0.0 \\
Talking to your doctor/professional & 13 & 25.0 & 41.7 & 33.3 \\
Interacting with someone who is nice to you & 27 & 25.0 & 70.8 & 4.2 \\
Doing household chores & 13 & 25.0 & 66.7 & 8.3 \\
Taking a hot bath or shower & 16 & 21.4 & 71.4 & 7.1 \\
Relaxing & 11 & 20.0 & 50.0 & 30.0 \\
Being around people & 22 & 20.0 & 40.0 & 40.0 \\
Setting limits on frequency of self-harm & 13 & 16.7 & 58.3 & 25.0 \\
Receiving outpatient counseling & 15 & 15.4 & 53.8 & 30.8 \\
Thinking about how much it will hurt & 15 & 15.4 & 53.8 & 30.8 \\
Listening to music & 25 & 13.6 & 59.1 & 13.6 \\
Doing mindless activities & 19 & 11.8 & 58.8 & 29.4 \\
Thinking about others with similar problems & 15 & 8.3 & 41.7 & 50.0 \\
Closing eyes and thinking calming thoughts & 13 & 7.7 & 69.2 & 23.1 \\
Finding a less chaotic environment & 16 & 7.1 & 57.1 & 35.7 \\
Reading & 17 & 6.7 & 60.0 & 33.3 \\
\hline & & & & \\
\hline
\end{tabular}

${ }^{a}$ These figures indicate the number of participants who endorsed having used each method at least once for the purpose of resisting an urge to self-injure.

${ }^{b}$ This table presents helpfulness ratings for coping methods that were used by at least 10 participants. Participants could rate each method they had tried as being "Very helpful," "Somewhat helpful," or "Not at all helpful" for resisting urges to self-injure.

exercise. That physical exercise may better help people calm down and avoid self-injury is not as readily apparent.

That the most common methods were not rated as the most helpful ones has treatment implications. It is useful for clinicians to know which methods are more or less successful in reducing urges to self-injure, and to distinguish these from methods that are simply more common or popular. Helpful methods can be emphasized and incorporated into treatment plans for self-injurers. For example, many psychologists encourage clients to minimize or eliminate access to the implement used to self-injure. The present study's results support this approach, 
and indicate that a majority of self-injurers may find this to be an effective and practical step for reducing self-injury. In addition, results suggest that exercise may provide an adaptive alternative to self-injury. This finding is consistent with recent research by Wallenstein and Nock (2007). In their case study, physical exercise led to substantial reductions in self-injurious thoughts and behaviors. In light of results both from the present study and from Wallenstein and Nock, future research should examine physical exercise as a treatment for self-injury in a formal, randomized controlled trial.

The present study represents a preliminary look at methods used by self-injurers to resist self-injurious urges. One limitation of the current study is the nature of the sample, which consists of college students. Future research should assess attempts to resist urges to self-injure in diverse samples. In addition, future studies should assess psychopathology of participants both to ensure a well-defined sample and to determine if subgroups with different clinical profiles may experience and react to self-injurious urges in different ways. Further, the coping methods measure used in this study is new and currently lacks information about reliability and validity. Future research would benefit from an instrument with established psychometric properties. Lastly, the current study used retrospective self-report measures to assess the history of self-injury. Future research in this area should consider utilizing diary methods whereby real-time information about self-injurious urges and relevant contextual features can be obtained. It is hoped that findings from this study will help psychologists supplement and enhance treatment for clients who self-injure.

\section{Acknowledgements}

Preparation of this study was supported by grant MH67299 from the National Institute of Mental Health and by the Office of the Vice President of Research at Stony Brook University.

\section{References}

Andover, M. S., Pepper, C. M., Ryabchenko, K. A., Orrico, E. G. and Gibb, B. E. (2005). Selfmutilation and symptoms of depression, anxiety, and borderline personality disorder. Suicide and Life-Threatening Behavior, 35, 581-591.

Briere, J. and Gil, E. (1998). Self-mutilation in clinical and general population samples: prevalence, correlates, and functions. American Journal of Orthopsychiatry, 68, 609-620.

Brown, M. (1998). Self-Mutilation, Treatment Research Symposium: the behavioral treatment of selfmutilation. Proceedings of the XVI Congress of the World Association for Social Psychiatry, 1998, Vancouver B.C., Canada.

Brown, M., Comtois, K. A. and Linehan, M. M. (2002). Reasons for suicide attempts and nonsuicidal self-injury in women with borderline personality disorder. Journal of Abnormal Psychology, 111, 198-202.

Carroll, J., Schaffer, C., Spensley, J. and Abramowitz, S. I. (1980). Family experiences of selfmutilating patients. American Journal of Psychiatry, 137, 852-853.

Claes, L., Vandereycken, W. and Vertommen, H. (2007). Self-injury in female versus male psychiatric patients: a comparison of characteristics, psychopathology and aggression regulation. Personality and Individual Differences, 42, 611-621.

Darche, M. A. (1990). Psychological factors differentiating self-mutilating and non-self-mutilating adolescent inpatient females. The Psychiatric Hospital, 21, 31-35. 
DiClemente, R. J., Ponton, L. E. and Hartley, D. (1991). Prevalence and correlates of cutting behavior: risk for HIV transmission. Journal of the American Academy of Child and Adolescent Psychiatry, 151, 1305-1311.

Evren, C. and Evren, B. (2005). Self-mutilation in substance-dependent patients and relationship with childhood abuse and neglect, alexithymia, and temperament and character dimensions of personality. Drug and Alcohol Dependence, 80, 15-22.

Favazza, A. R., DeRosear, L. and Conterio, K. (1989). Self-mutilation and eating disorders. Suicide and Life-Threatening Behavior, 19, 352-361.

Gratz, K. L. (2001). Measurement of deliberate self-harm: preliminary data on the Deliberate Self-Harm Inventory. Journal of Psychopathology and Behavioral Assessment, 23, 253-263.

Gratz, K. L. (2006). Risk factors for deliberate self-harm among female college students: the role and interaction of childhood maltreatment, emotional inexpressivity, and affect intensity/reactivity. American Journal of Orthopsychiatry, 76, 238-250.

Gratz, K. L. and Gunderson, J. G. (2006). Preliminary data on an acceptance-based emotion regulation group intervention for deliberate self-harm among women with borderline personality disorder. Behavior Therapy, 37, 25-35.

Hawton, K., Rodham, K., Evans, E. and Weatherall, R. (2002). Deliberate self harm in adolescents: self report survey in schools in England. British Medical Journal, 325, 1207-1211.

Herpertz, S. (1995). Self-injurious behavior: psychopathological and nosological characteristics in subtypes of self-injurers. Acta Psychiatrica Scandinavia, 91, 57-68.

Hilt, L. M., Nock, M. K., Lloyd-Richardson, E. E. and Prinstein, M. J. (in press). Longitudinal study of non-suicidal self-injury among young adolescents: rates, correlates, and preliminary test of an interpersonal model. Journal of Early Adolescence.

Klonsky, E. D. (2007). The functions of deliberate self-injury: a review of the evidence. Clinical Psychology Review, 27, 226-239.

Klonsky, E. D. and Moyer, A. (in press). Childhood sexual abuse and non-suicidal self-injury: metaanalysis. British Journal of Psychiatry.

Klonsky, E. D. and Olino, T. M. (in press). Identifying clinically distinct subgroups of self-injurers among young adults: a latent class analysis. Journal of Consulting and Clinical Psychology.

Klonsky, E. D., Oltmanns, T. F. and Turkheimer, E. (2003). Deliberate self-harm in a nonclinical population: prevalence and psychological correlates. American Journal of Psychiatry, 160, 15011508.

Koerner, K. and Dimeff, L. A. (2000). Further data on dialectical behavior therapy. Clinical Psychology: Science and Practice, 7, 104-112.

Laye-Gindhu, A. and Schonert-Reichl, K. A. (2005). Nonsuicidal self-harm among community adolescents: understanding the "whats" and "whys" of self-harm. Journal of Youth and Adolescence, $34,447-457$.

Linehan, M. (1993). Cognitive-Behavioral Therapy for Borderline Personality Disorder. New York: Guilford Press.

Linehan, M. M., Armstrong, H. E., Suarez, A., Allmon, D. and Heard, H. L. (1991). Cognitivebehavioral treatment of chronically parasuicidal borderline patients. Archives of General Psychiatry, 48, 1060-1064.

Linehan, M. M., Comtois, K. A., Murray, M. A., Brown, M. Z., Gallop, R. J., Heard, H. L., Korslund, K. E., Tutek, D. A., Reynolds, S. K. and Lindenboim, N. (2006). Two-year randomized controlled trial and follow-up of dialectical behavior therapy vs. therapy by experts for suicidal behaviors and borderline personality disorder. Archives of General Psychiatry, 63, 757766.

Linehan, M. M., Heard, H. L. and Armstrong, H. E. (1993). Naturalistic follow-up of a behavioral treatment for chronically parasuicidal borderline patients. Archives of General Psychiatry, 50, 971974. 
Muehlenkamp, J. J. and Gutierrez, P. M. (2004). An investigation of differences between self-injurious behavior and suicide attempts in a sample of adolescents. Suicide and Life-Threatening Behavior, 34, $12-23$.

Nock, M. K. and Prinstein, M. J. (2004). A functional approach to the assessment of self-mutilative behavior. Journal of Consulting and Clinical Psychology, 72, 885-890.

Nock, M. K. and Prinstein, M. J. (2005). Contextual features and behavioral functions of self-mutilation among adolescents. Journal of Abnormal Psychology, 114, 140-146.

Rodham, K., Hawton, K. and Evans, E. (2004). Reasons for deliberate self-harm: comparison of selfpoisoners and self-cutters in a community sample of adolescents. Journal of the American Academy of Child and Adolescent Psychiatry, 43, 80-87.

Ross, S. and Heath, N. (2002). A study of the frequency of self-mutilation in a community sample of adolescents. Journal of Youth and Adolescence, 31, 67-77.

Scheel, K. R. (2000). The empirical basis of dialectical behavior therapy: summary, critique, and implications. Clinical Psychology: Science and Practice, 7, 68-96.

Stanley, B., Gameroff, M. J., Michalsen, V. and Mann, J. J. (2001). Are suicide attempters who self-mutilate a unique population? American Journal of Psychiatry, 158, 427-432.

Swenson, C. R., Torrey, W. C. and Koerner, K. (2002). Implementing dialectical behavior therapy. Psychiatric Services, 53, 171-178.

Wallenstein, M. B. and Nock, M. K. (2007). Physical exercise for the treatment of non-suicidal selfinjury: evidence from a single-case study. American Journal of Psychiatry, 164, 350-351.

Whitlock, J., Eckenrode, J. and Silverman, D. (2006). Self-injurious behaviors in a college population. Pediatrics, 117, 1939-1948.

Zlotnick, C., Mattia, J. I. and Zimmerman, M. (1999). Clinical correlates of self-mutilation in a sample of general psychiatric patients. Journal of Nervous Mental Disease, 187, $296-301$.

Zoroglu, S. S., Tuzun, U., Sar, V., Tutkun, H., Savas, H. A., Ozturk, M., Alyanak, B. and Kora, M. E. (2003). Suicide attempt and self-mutilation among Turkish high school students in relation with abuse, neglect, and dissociation. Psychiatry and Clinical Neurosciences, 57, 119-126.

Zweig-Frank, H., Paris, J. and Guzder, J. (1994). Psychological risk factors for dissociation and selfmutilation in female patients with borderline personality disorder. Canadian Journal of Psychiatry, 39, 259-264. 